\title{
Probabilities of Storage States of Real Time Reservoir System
}

\author{
$\underline{\text { Dr. Kamel A. Al-Mohseen }}{ }^{* *}$
}

\begin{abstract}
The long-term probabilities of storage states of Bakhma reservoir system at northern part of Iraq have been investigated. The seasonal probability transition matrices have been manipulated in different orders to construct the yearly probability transition matrices where the latter were implemented to calculate the steady state probabilities. The results reveal that the final state of the system depends upon how one can manipulate the seasonal transition matrices in an appropriate order. Additionally, it was found that Bakhma reservoir workable storage is either underestimated and should be re-evaluated or the turbine capacity has to be increased to generate additional power, otherwise, significant amount of water might be lost over the spillway.
\end{abstract}

Keywords:Transition matrix, Long Term Probabilities, Reservoir Storage Estimation

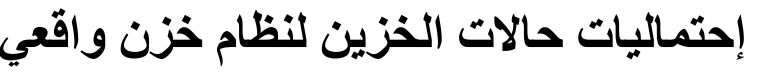

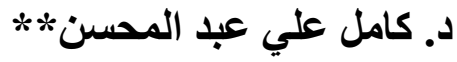

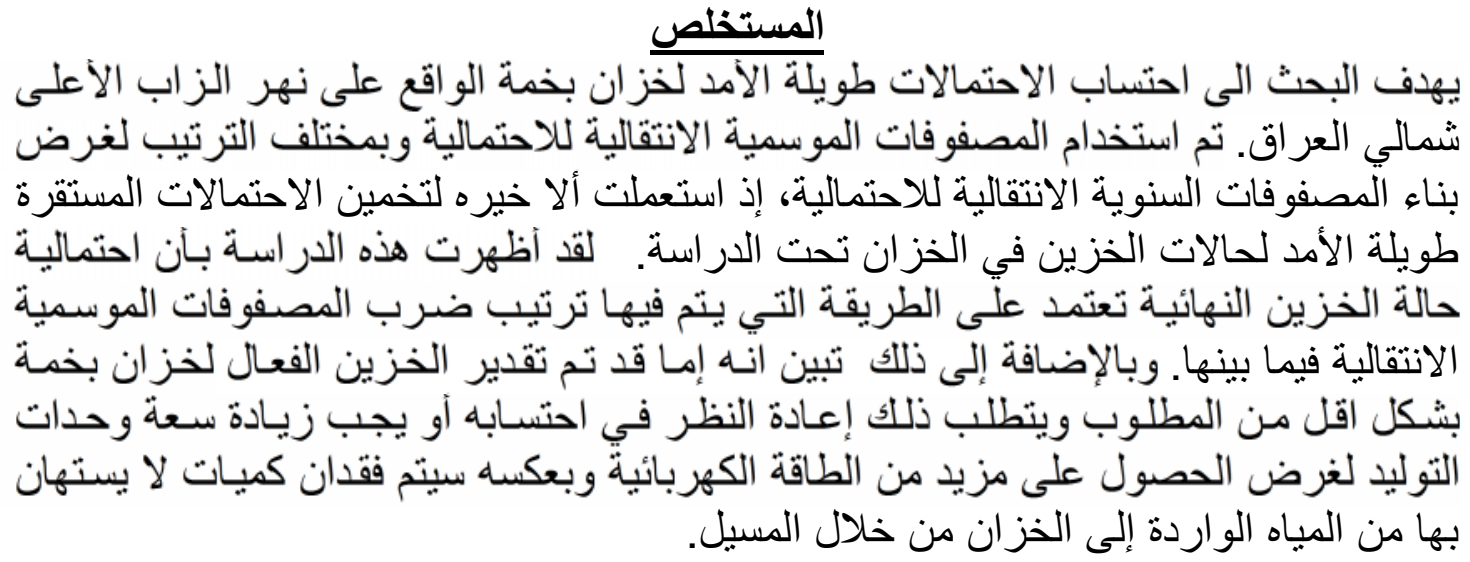

** Assistant Professor - Water Resources Engineering Department - University of Mosul

**

\section{Introduction}

Water stored in reservoirs is considered one of the most important sources of supply for the neBegeitheq among the various and often, competing demands. 
The difficulty usually arises is due the fact that the river inflow into a certain reservoir is stochastic in nature. The management procedures of any reservoir system meeting a specific demand depends upon three factors: the quantity and variability of inflow, the size of demand, and the degree of reliability of such demand being met.

The present study would focus on the third factor mentioned above, i.e. the degree of reliability for a real time reservoir system "at planning phase" in meeting certain demand. The reliability problem can be well addressed through probability theory applied to reservoir storage problems. The main criteria in planning and design of an individual reservoir is the probability of failure. A more direct approach can be adopted if the inflow data are independent or have Markov type dependence. The choice among alternatives is usually made so that this probability does not exceed a stipulated value, which depends on the purpose served. Another interesting outcomes are the number of times a reservoir will spill or empty during a given period and the probability of first emptiness as well.

\section{Markov Process (Theoretical Background)}

Moran (1959) in his book "Theory of Storage", initiated the probability theory applied to reservoir storage problems based on serially independent reservoir inflows with fixed distribution. Moran's theory has been extended in the past four decades or so with notable practical contributions because this theory was considered the time as a continuous variable. Generally, the continuous time model is the most complex and least realistic among the various classes of models.

Gould (1961) modified Moran's theory and applied it to monthly data. Probabilities of various reservoir states at the end of a year are evaluated for the cases when both inflows and outflows are continuous, but as in many other applications, discrete reservoir states are taken in to account.

The Markov process model is widely used in engineering practice to describe natural time series. It is a conceptual model assumes that the states of the system are governed by the previous states through certain probability laws. Mathematically speaking and for $\mathrm{m}>0$

$$
F_{x}\{X(t+m) \mid X(t), X(t+1), X(t+2), \ldots .\}=F_{x}\{X(t+m) \mid X(t)\}
$$

where:

$\mathbf{F}_{\mathbf{X}}(\mathbf{X})$ is the cumulative distribution function of random variable $x$, which is the probability that the value of $\mathbf{X}$ is less than or equal to $x$.

A special kind of Markov process is one whose state $X(t)$ can take on only discrete values. Such a process is called Markov chain. Often in water resources planning, continuous 
stochastic processes are approximated by Markov chains (Loucks et. al. 1981). Markov chain requires specification of the transition probabilities or simply transition matrix.

By discretizing reservoir storage volume into finite number of states and regarding the operation process as a transition of storage from one state in any given time period to another in the succeeding time period, reservoir operations are often viewed as a Markov decision processes. This can be expressed by the continuity equation (neglecting evaporation and other issues):

$Z_{t+1}=Z_{t}+X_{t}-R$

Subject to:

$0 \leq \mathrm{Z}_{\mathrm{t}+1} \leq \mathrm{C}$

Where:

$\boldsymbol{Z}_{t+1}$ and $\boldsymbol{Z}_{t}=$ volume of water stored at the beginning of time step $t$ and $t+1$ respectively. $\mathbf{X}_{\mathrm{t}}=$ the inflow in time step $\mathrm{t}$.

$\mathbf{R}=$ the constant draft in time step $\mathrm{t}$.

C = Reservoir storage capacity.

(All terms in Eq. (2) are expressed in the same unit volume (i.e. Million Cubic Meter)).

Lloyed (1963) extended Moran's theory taking into account the serial correlation of inflows. A bivariate Markov chain was formulated to describe the simultaneous behavior of inflows and reservoir states on the assumption that the inflows are following Markov chain too. That is instead of writing the probability of transition from state $Z_{t}$ to state $Z_{t+1}$ in Eq. (1), probabilities of transition from $\left(\mathbf{Z}_{t}, \mathbf{X}_{t}\right)$ to $\left(\mathbf{Z}_{t+1}, \mathbf{X}_{t+1}\right)$ are entered, (i.e. the inflow probabilities are entered against each reservoir state). Kottagoda (1980) reported that the solution of steady state probabilities requires a large number of simultaneous equations.

\section{$\underline{\text { Bakhma Reservoir -A Case Study }}$}

In seeking a solution for seasonal changes in the probability distribution of inflows within annual cycle, Lloyed and Odoom (1964) suggested the division of a year into $k$ seasons and had used different one-step transition matrix for each individual season. Solutions to simultaneous equations relating the steady state probabilities of reservoir states at the end of a year are made after multiplying the transition matrices in the appropriate order. 
Recognizing the need to minimize the gap between theory and practice, the present paper is an attempt to apply the transition probability matrix approach to a practical useful case where Bakhma reservoir at northern part of Iraq has been selected to investigate the longterm probability of storage. Bakhma reservoir (under construction), is located on the Greater Zab river, upstream of Eski-Kelek gauging station. Recently, Gazzal (2002) has reported the pertinent parameters relevant to Bakhma reservoir. He quantified the minimum and maximum operating storage as 4470 and 13670 (million cubic meters) respectively. He indicated that the power plant capability of this reservoir is to generate $1560 \mathrm{MW}$. The mean monthly flow at Eski-Kelek gauging station is used as a set of inflows to the system where 68 years of mean monthly flow are available.

On the contrary to what usually appears in literatures, where researchers used to divide the year into two seasons for seek of simplicity, the year in the present work is divided into four seasons, (i.e.,autumn (October to December), winter (January to March), spring (April to June), and summer (July to September)).

Markov chain requires specification of the transition probabilities or simply transition matrix. The transition probabilities which dictate the likelihood of transition from one state to another, can be calculated directly from the historical data by grouping these data into corresponding discrete state transitions, (Lee et. al. 1987). Figure (1) below shows the relative frequencies of the four seasons and using four classes (states) for inflow data for convenience.

The relative frequencies of these mutually exclusive events can then be used to compute the probabilities of changing from one specific state to each of possible states in the subsequent period. For example, autumn season is divided into the classes $(875,1625,2375$, and 3125$)$, while winter is divided to $(1688,3563,5438$, and 7313$)$ Million Cubic Meter respectively, where these figures represent the central value of each class interval appears in Figure (1) for autumn and winter histograms. The seasonal transition matrix in Table 1, summarized the conditional probabilities.

Note that in column 1 - row 1 of the upper-left matrix, the value of the probability is 0.5 . This value is obtained by dividing the number of times that the flow in winter season being in the first class given that the flow in the previous autumn season being in the first class too, by the total number of years that the flow in autumn season being in the first class. The remains of the entries have been calculated in the same way.

This method is assumed to be feasible for the current work where the historical data base (68 years of monthly flows) is considered large enough to characterize the whole spectrum of transition probabilities properly.

\section{Assumptions Made}

The following assumptions have been made:

1. The assessment of the long term probabilities of reservoir states required a sufficient length of flow data, consequently, the flows at Eski-Kelek gauging 
station have been considered as an input to the system which is considered a reasonable assumption in the absence of recorded inflow to Bakhma reservoir.

2. Seasonal inflows are assumed to be independent, i.e the lag one autocorrelation for each specific season is zero. Tests carried out to confirm this fact shows that lag-one auto-correlation for Autumn, Winter, Spring and Summer are $(0.176,0.069,-0.075$, and 0.233 respectively) which can be reasonably assumed insignificant and close to zero.

3. The technique assumes constant seasonal drafts from the reservoir of 2000,4500,1200, and 1000 ( Million cubic meter) for Autumn, Winter, Spring and Summer respectively. These figures have been taken from Gazzal (2002), in which they were representing the seasonal drafts corresponding to the optimal operation of the reservoir to produce maximum electric power. Where the operating policy based on the maximization of hydropower generation which derived by Gazzal, is considered a constructive one as the main objective of Bakhma reservoir is to generate electric power.

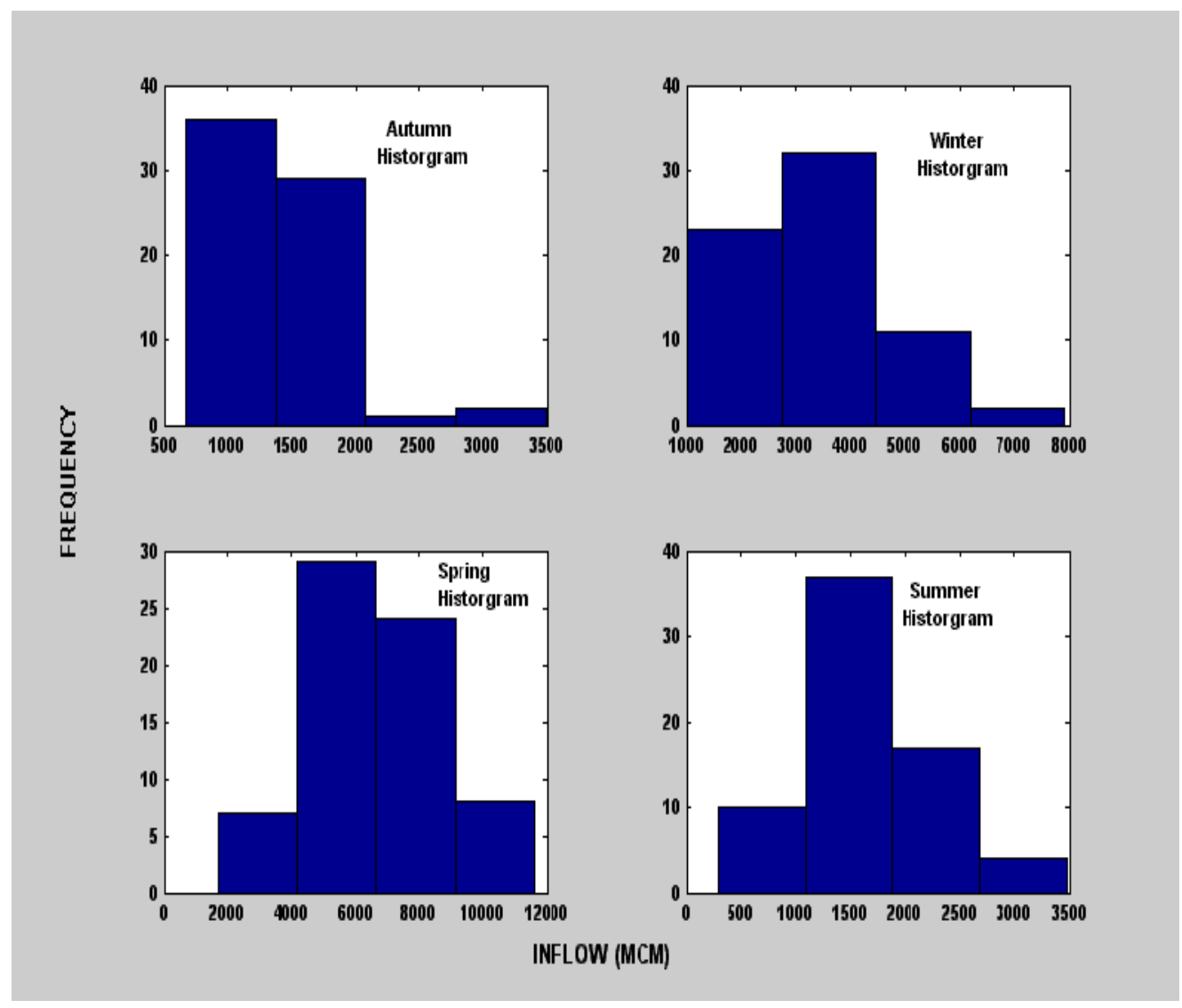

Figure (1) Relative frequencies of the four seasons used in the study

Table 1. Conditional seasonal transition matrices in terms of inflow alone.

\begin{tabular}{|c|c|c|c|c|c|c|c|}
\hline \multicolumn{4}{|c|}{ AUTUMN - WINTER MATRIX } & \multicolumn{4}{|c|}{ "WINTER - SPRING MATRIX } \\
\hline 0.5 & 0.2 & 0.2 & 0.0 & 0.2 & $\mathbf{0 . 0}$ & $\mathbf{0 . 0}$ & $\mathbf{0 . 0}$ \\
\hline
\end{tabular}




\begin{tabular}{|c|c|c|c|c|c|c|c|}
\hline $\bar{~} 0.4$ & $\bar{~} 0.6$ & $\overline{c 0.8}$ & $\bar{~} 0.0$ & $\overline{0.6}$ & 0.4 & $\bar{~} 0.1$ & 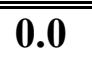 \\
\hline 0.1 & 0.2 & 0.0 & 0.0 & 0.2 & 0.5 & 0.6 & 0.0 \\
\hline 0.0 & 0.0 & 0.0 & 1.0 & 0.0 & 0.1 & 0.3 & $\mathbf{1 . 0}$ \\
\hline \multicolumn{4}{|c|}{ SIPRING - SUMMER MATRIX } & \multicolumn{4}{|c|}{ SUMMER-AUTUMN MATRI } \\
\hline 0.5 & 0.5 & 0.2 & 0.0 & 0.7 & 0.3 & 0.0 & 0.5 \\
\hline 0.5 & 0.5 & 0.8 & 0.9 & 0.3 & 0.6 & 0.5 & 0.5 \\
\hline 0.0 & 0.0 & 0.0 & 0.1 & 0.0 & 0.1 & 0.5 & 0.0 \\
\hline $\mathbf{0 . 0}$ & 0.0 & 0.0 & 0.0 & 0.0 & 0.0 & 0.0 & 0.0 \\
\hline
\end{tabular}

Probability matrix solutions are affected by zone size and hence the number of zones (states). It is thought that 10 reservoir states may suffice for design purposes, this may reduced to five states for rough calculations, (Kottegoda, 1980). McMahon and Mein (1986) stated that it is prudent to use a small number of storage states to reduce computer requirements. Six states have been adopted here. Tables 2 through 5 present the transition matrices in terms of inflows and storage states from one season to the following season. For example $\mathrm{M}_{1}$ represents the transition probability matrix where the system is in winter season at the current state and it is in spring season at the following state. While $\mathrm{M}_{4}$ is in autumn at the current state and it is in winter at the next state and so forth for the matrices $\mathrm{M}_{2}$ and $\mathrm{M}_{3}$.

Kottegoda (1980) concluded that the yearly probability matrix of reservoir states at the end of a year are made after multiplying the transition matrices (i.e. $M_{1}, M_{2}, M_{3}$ and $\mathrm{M}_{4}$ ) in the appropriate order. The following combinations have been worked out:

$$
\begin{aligned}
& \mathrm{Q}_{1}=\mathrm{M}_{1} * \mathrm{M}_{2} * \mathrm{M}_{3} * \mathrm{M}_{4} \\
& \mathrm{Q}_{2}=\mathrm{M}_{2} * \mathrm{M}_{3} * \mathrm{M}_{4} * \mathrm{M}_{1} \\
& \mathrm{Q}_{3}=\mathrm{M}_{3} * \mathrm{M}_{4} * \mathrm{M}_{2} * \mathrm{M}_{1} \\
& \mathrm{Q}_{4}=\mathrm{M}_{4} * \mathrm{M}_{1} * \mathrm{M}_{2} * \mathrm{M}_{3}
\end{aligned}
$$

It has been noticed that the obtained yearly matrices (i.e. Q's) are not identical, rather, they are totally differs from each other. Tables 6 through 9 view this finding. 
Table 2. Winter - Spring Transition Matrix (M1)

Reservoir State at the Start of Winter Season

Storage Classes (MCM)

4500-6000

$6000-7500$

$7500-9000$

9000-10500

10500-12000

12000-1:

Average Inflow Classes (MCM)

建

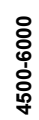

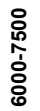

茟

建

茟

䢖

萧

萧

建

烡

茟

${ }^{3563}$

Table 3. Spring - Summer Transition Matrix (M2)

Storage Classes (MCM) 
Table 4. Summer - Autumn Transition Matrix (M3)

Reservoir State at the Start of Summer Season

Storage Classes (MCM)

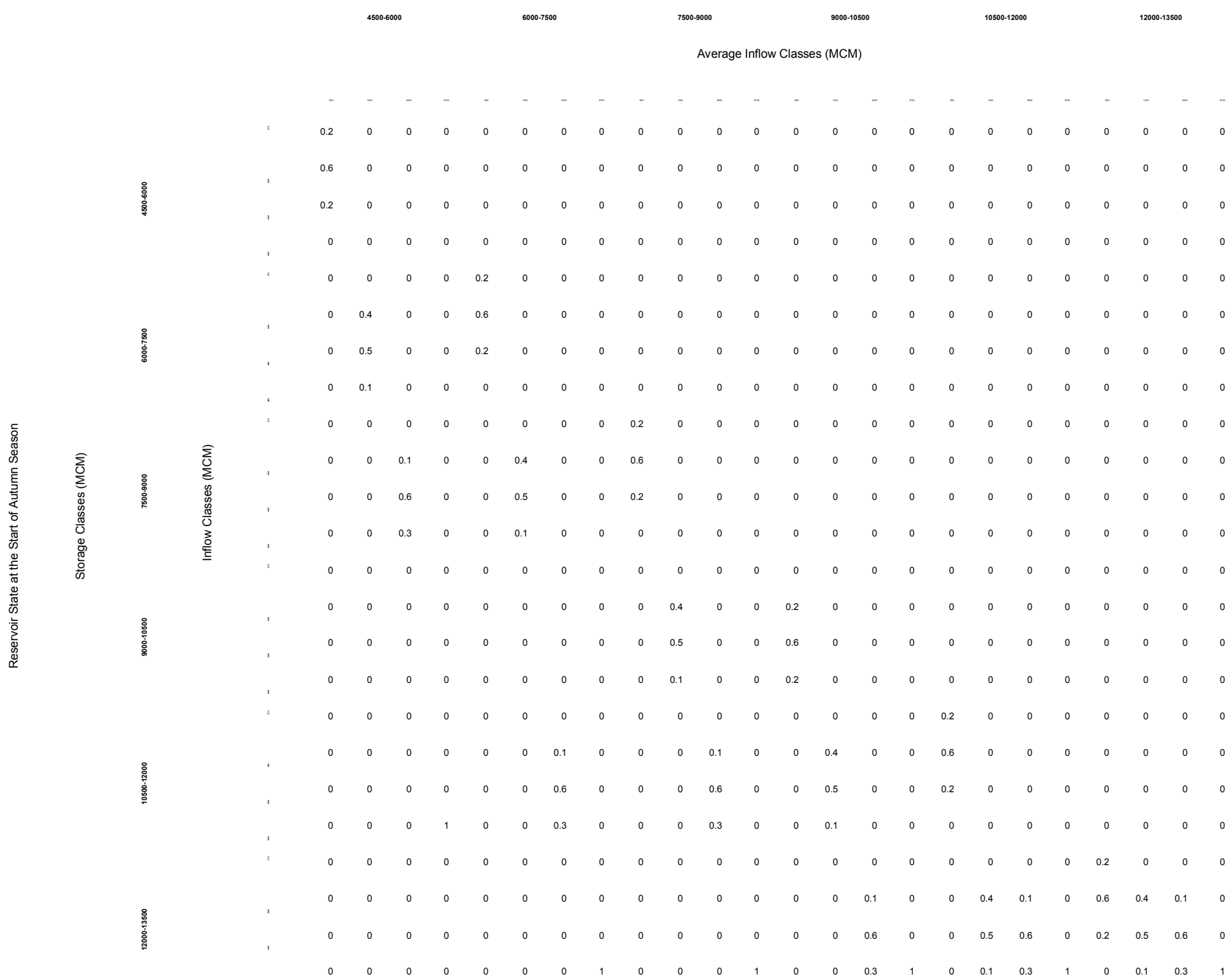

Table 5. Autumn - Winter Transition Matrix (M4)

Reservoir State at the Start of Autumn Season

Storage Classes (MCM)

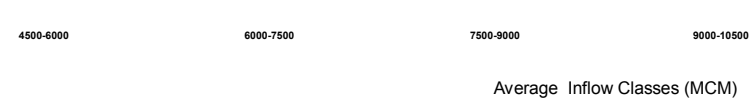

Average Inflow Classes (MCM)

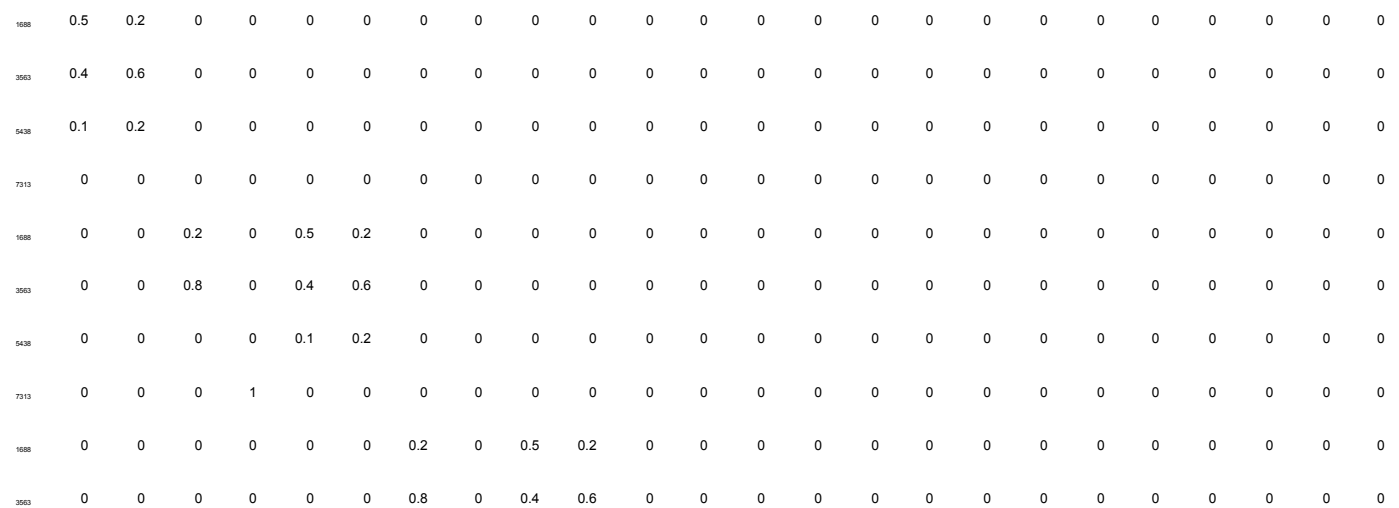




\section{Steady State Probabilities}

Let $\mathrm{Q}$ be the transition matrix whose elements are $\mathrm{q}_{\mathrm{ij}}$. For Markov chain, the transition matrix contains all the information necessary to describe the behavior of the system. Let $\mathrm{q}_{\mathrm{i}}^{\mathrm{y}}$ be the probability that the system resides in state $i$ in year $y$. Then the probability that $\mathrm{Q}_{\mathrm{y}+1}=\mathrm{q}_{\mathrm{j}}$ is the sum of the probabilities $\mathrm{p}_{\mathrm{i}}^{\mathrm{y}}$ that $\mathrm{Q}_{\mathrm{y}}=\mathrm{q}_{\mathrm{i}}$ times the probability $\mathrm{p}_{\mathrm{ij}}$ that $\mathrm{Q}_{\mathrm{y}+1}=\mathrm{q}_{\mathrm{j}}$ given that $\mathrm{Q}_{\mathrm{y}}=\mathrm{q}_{\mathrm{i}}$; Mathematically,

$\mathbf{p}_{\mathrm{j}}{ }^{\mathrm{y}+1}=\mathbf{p}_{1}{ }^{\mathrm{y}} \mathbf{p}_{1 \mathrm{j}}+\mathbf{p}_{2}{ }^{\mathrm{y}} \mathbf{p}_{2 \mathrm{j}}+\ldots \ldots+\mathbf{p}_{\mathrm{n}}^{\mathrm{y}} \mathbf{p}_{\mathrm{nj}}=\sum_{=\mathrm{i}}^{\mathrm{n}} \mathbf{p}_{\mathrm{i}}^{\mathrm{y}} \mathbf{p}_{\mathrm{ij}}$

The steady-state probabilities of any Markov chain can be found by solving simultaneous equations given in Eq. (3) above. It will be found that these $\boldsymbol{n}$ equations are not independent. To get a solution of any one of them, it must be replaced by the equation:

$$
\sum_{i=1}^{n} P_{i}=\mathbf{1}
$$

Solving for $\mathbf{Q}_{\mathbf{1}}$ through $\mathbf{Q}_{\mathbf{4}}$ result in the steady state vectors presented in Table 10 .

Table 10. Steady State Vectors of the four yearly transition matrices.

\begin{tabular}{|c|ccccccccccccccccccccccc|}
\hline \multicolumn{11}{c|}{ Steady State Vectors of Yearly Transition Matrices } \\
\hline $\mathbf{q}_{1}=0$ & 0 & 0 & 0 & 0 & 0 & 0 & 0 & 0 & 0 & 0 & 0 & 0 & 0 & 0 & 0 & 0 & 0 & 0 & 0 & $\mathbf{0 . 2}$ & $\mathbf{0 . 7}$ & $\mathbf{0 . 1}$ & $\mathbf{0}$ \\
\hline $\mathbf{q}_{2}=0$ & 0 & 0 & 0 & 0 & 0 & 0 & 0 & 0 & 0 & 0 & 0 & 0 & 0 & 0 & 0 & 0 & 0 & 0 & 0 & $\mathbf{0 . 1}$ & $\mathbf{0 . 6}$ & $\mathbf{0 . 3}$ & $\mathbf{0}$ \\
\hline $\mathbf{q}_{3}=0$ & 0 & 0 & 0 & 0 & 0 & 0 & 0 & 0 & 0 & 0 & 0 & 0 & 0 & 0 & 0 & 0 & 0 & 0 & 0 & $\mathbf{0 . 5}$ & $\mathbf{0 . 5}$ & $\mathbf{0}$ & $\mathbf{0}$ \\
\hline $\mathbf{q}_{4}=0$ & 0 & 0 & 0 & 0 & 0 & 0 & 0 & 0 & 0 & 0 & 0 & 0 & 0 & 0 & 0 & 0 & 0 & 0 & 0 & $\mathbf{0 . 4}$ & $\mathbf{0 . 5}$ & $\mathbf{0 . 1}$ & $\mathbf{0}$ \\
\hline
\end{tabular}

\section{$\underline{\text { Results and Conclusions }}$}

Different combinations from multiplication of seasonal matrices $\mathrm{M}_{1}, \mathrm{M}_{2}, \mathrm{M}_{3}$, and $\mathrm{M}_{4}$ in various orders result in different yearly transition matrices $\mathrm{Q}_{1}, \mathrm{Q}_{2}, \mathrm{Q}_{3}$, and $\mathrm{Q}_{4}$. Consequently, different steady states vectors $\left(\mathrm{q}_{1}, \mathrm{q}_{2}, \mathrm{q}_{3}\right.$, and $\left.\mathrm{q}_{4}\right)$ have been obtained. Such results are considered interesting, as they had not been reported in literatures yet. This might be attributed to the weak correlation exists among seasons considered in this study (i.e. the four seasons inflows are not completely independent). Additionally, the results reveal that whatever the initial state at Bakhma reservoir is to be started with, the long-term probabilities are always end at full conditions (state). This imply that either the workable storage capacity had been underestimated and should be re-evaluated or the capacity of the turbines are to be increased to generate more power while reducing the water that might be lost over the spillway. 
Table 6. Yearly Transition Matrix (Q1=M1.M2.M3.M4)

Reservoir State at the Start of Current Year

Storage Classes (MCM)

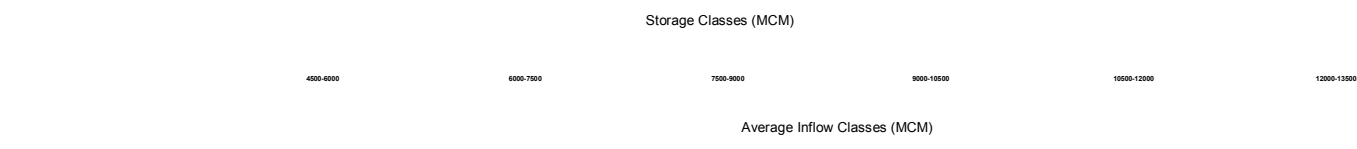

1

1

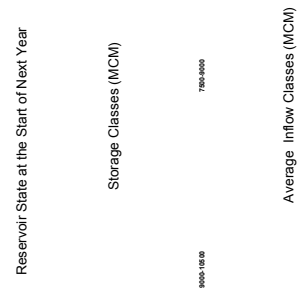

1

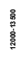

Table 7. Yearly Transition Matrix (Q2=M2.M3.M4.M1)

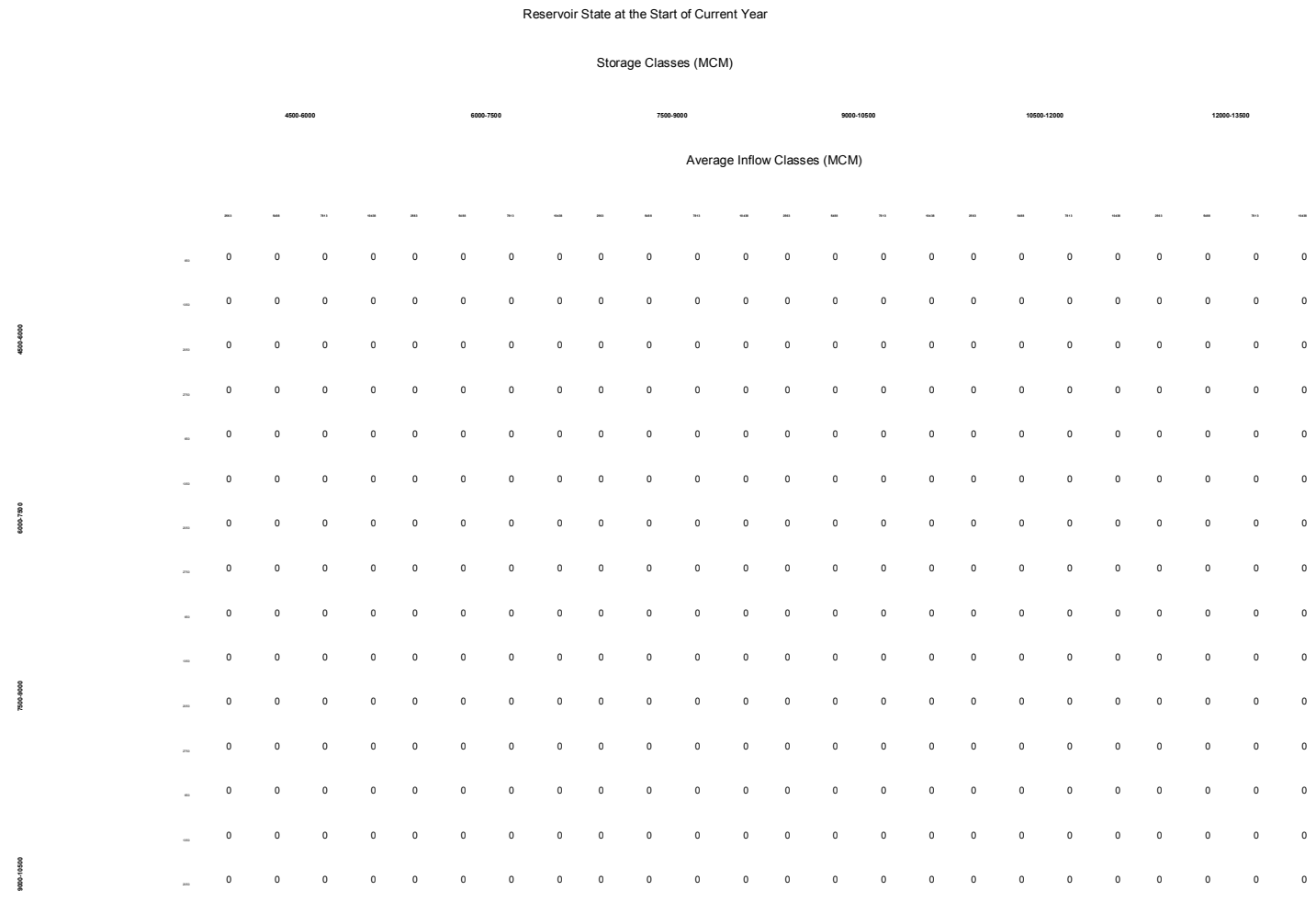




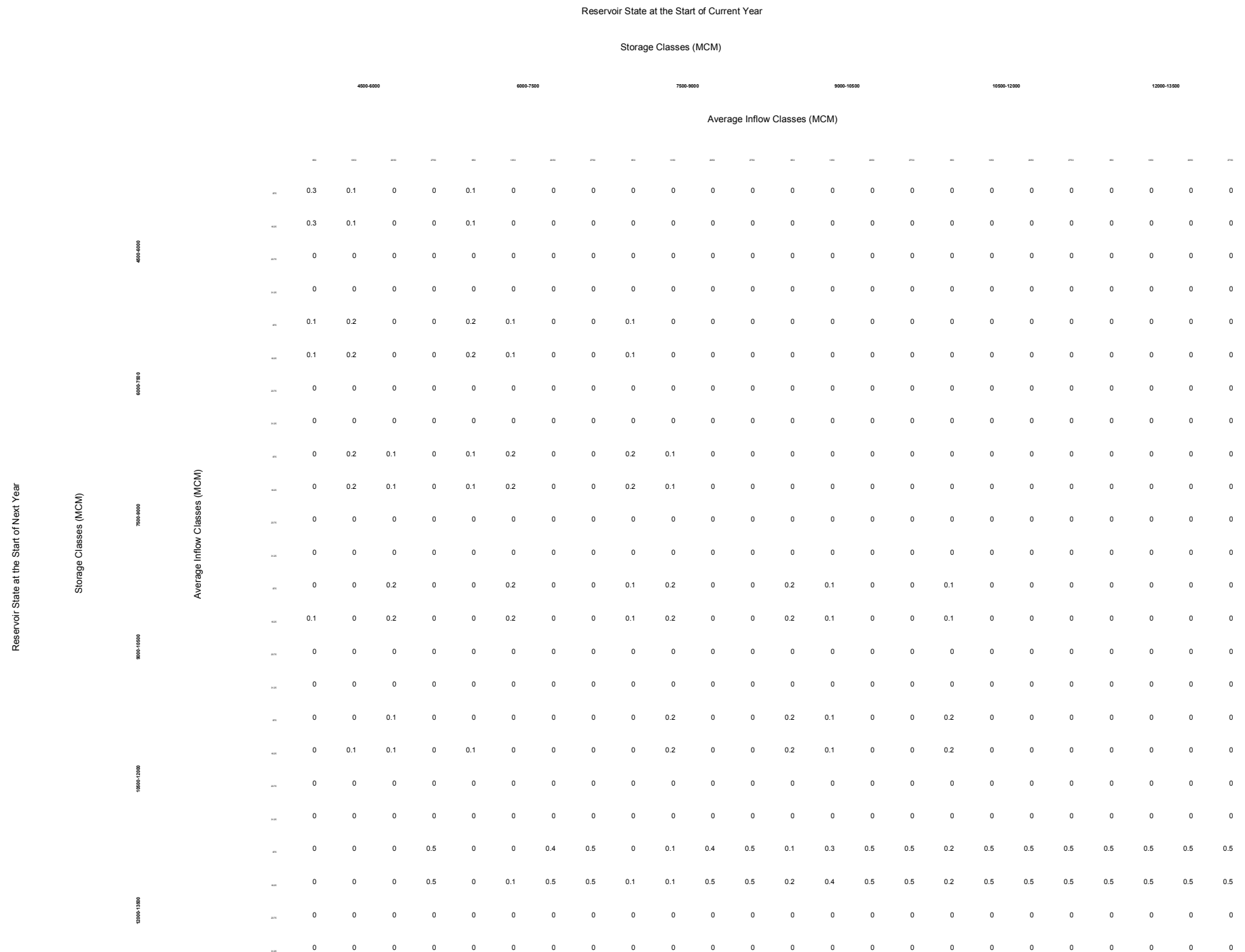

Table 9. Yearly Transition Matrix (Q4=M4.M1.M2.M3)

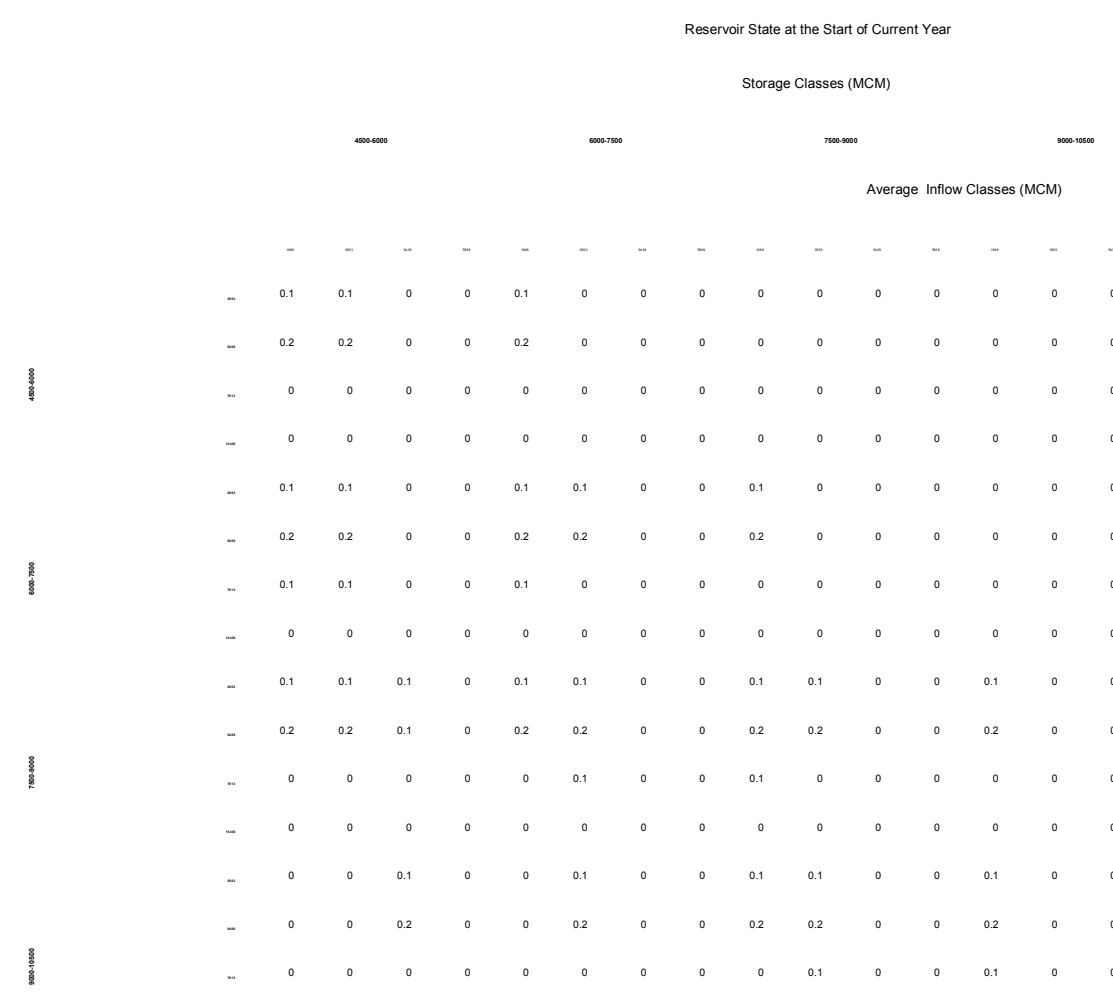




\section{$\underline{\text { References }}$}

Gazzal, A. Al-Wahab, " Optimal water utilization from Tigris basin reservoirs North of Fatha for hydroelectric power generation", Ph.D. Thesis, Water Resources Department, University of Mosul, Iraq, (2002).

Gould, B. W., "Statistical methods for estimating the design capacity of dams", J. Inst. Eng. Aust., 33, 405-416, (1961).

Kottegoda, N. T., " Stochastic Water Resources Technology ", John Wiley \& Sons, New York,(1980).

Lee, H-L., E. D. Brill and J. C. Liebman, "Reliability of reservoir operation under hydrologic uncertainty", Research report 207, Water Research Center, Illinois, USA.(1987).

Lloyd, E. H., "A probability theory of reservoirs with serially correlated inputs" J. Hydrol., 1, 99-128, (1963).

Lloyd, E. H., and S. Odoom, " Probability theory of reservoirs with seasonal input",J. Hydrol.,2, 1-10, (1964).

Loucks, D. P., J. R. Stedinger, and D. A. Haith, "Water Resource Systems Planning and Analysis", Prentice-Hall, N. J..(1981).

Mc Mahon, T. A. and R. G. Mein, " River and Reservoir Yield ",Water Resources Publications, Littleton, Colorado, U.S.A., (1986).

Moran, P. A. P., " The Theory of Storage ", Methuen, London, (1959). 